\title{
QUALITY AND GRADING RISK
}

\author{
ETHAN LIGON
}

\begin{abstract}
Processors, packer-shippers, integrators, and a variety of third-parties engage in a wide variety of different kinds of grading, intended to summarize quality characteristics of different kinds of foodstuffs. There are two ways in which these grading characteristics may be imperfect. First, they may fail to perfectly capture the variation in quality experienced by the eventual consumer; or second, may fail to perfectly reflect investments made by the producer to improve quality. Either (or both) of these kinds of imperfections has implications for prices, investments, consumer welfare, and contracts between producers and intermediary firms. In this chapter we explore possible consequences of imperfect grading, with selected illustrations for a variety of different commodities.
\end{abstract}

\section{INTRODUCTION}

Many (perhaps most) sorts of agricultural commodities are not homogeneous, but instead vary according to a set of quality characteristics. Some of these characteristics may be easy to inexpensively measure-many sorts of fresh fruit, for example, are sorted into different sizes by using a sizing belt. However, others may be difficult to measure non-destructively-think of trying to measure the color of the flesh of a whole melon. In between these extremes (characteristics which are easily measured and those which are difficult or impossible to non-destructively measure) lie the sorts of characteristics which consumers may place a high value on, yet which can only be easily measured by the prospective consumer, such as the smell of a tomato.

Choosing to purchase a commodity which bundles a variety of observable characteristics can be thought of as the hedonic choice of Lancaster

Date: April 18, 2001

Revision : 1.1 .

Key words and phrases. Grading Risk, Quality measurement, Agricultural Contracts, Efficient Contracts.

My thanks to Brent Hueth, my collaborator on much of the research which has informed my thinking on this subject. This research has been sponsored in part by NRI Competitive Grants Program/USDA award \#98-35400-6092 and by the Giannini Foundation, but the views expressed in this article are not endorsed by either of these sponsors. 
(1966). Here we want to consider the case in which an indivisible commodity can be regarded as a bundle of characteristics, but where not all of these characteristics are observed prior to consumption.

Not only might it be the case that some quality characteristics aren't observed by consumers, but it may also be the case that those same characteristics may be unobserved by the producer and any intermediaries. Indeed, actors upstream of the consumer may be able to observe even less than does the consumer. The way a fruit ripens over time adds some additional uncertainty to the problem faced by a wholesaler, for example. Other characteristics (think again of fragrance) may be easily observed by any actor, but may be difficult to communicate.

To some extent the producer or intermediary may have some control over the distribution of characteristics they can't directly observe-the timing of harvest will influence the ripeness perceived by the final consumer, for example. This control may mitigate the problems associated with the fact that some quality characteristics can't be observed, but may also add an interesting twist-if the actions taken by the producer influence eventual outcomes, but these actions are hidden from intermediaries and consumers, then this asymmetry can have a profound influence on the organization of an industry.

To this point, we've talked about "quality characteristics" without referring to "grades." We'll think of a grade as a particular categorization of some kind of produce according to its measurable quality characteristicsby assumption, the grade cannot convey more information than a complete description of characteristics, and will typically convey less. Often grading information is compiled by the government, or by some third party established under the auspices of a state or federal marketing order. ${ }^{1}$

The importance of grades varies considerably across different kinds of commodities. For example, Kansas wheat is graded by the state according to characteristics including weight per bushel, dockage and defects, protein content, and water content. These characteristics explain about 24 per cent of the variation in prices paid for wheat; additional characteristics which don't influence the grade but which are often privately measured (mostly having to do with the behavior of the grain as it's milled) account for an additional 17 per cent of the variation in price (Espinosa and Goodwin (1991), Table 4). In this case grading information appears to be relevant to purchasing decisions, but incomplete. To the extent that buyers must rely on private measurement for more subtle characteristics, it's not clear that the statesponsored grading system has much value in this case. A more extreme

\footnotetext{
${ }^{1}$ Dimitri, Horowitz, and Lichtenberg (1996) observe that the USDA uses grades to set quality standards for 92 distinct horticultural commodities, while grading is ubiquitous for meat in the US.
} 
case in which state-sponsored grading appears to have little usefulness is that of many fresh-market horticultural commodities. Grading information for most fresh fruits and vegetables (usually based on size and defects) is of such little use that information on grade is seldom communicated to the final consumer, who can see for himself whether the tomatoes are bruised and what their size is, but cares more about ripeness, information which isn't included in the grade (Bierlen and Grunewald 1995). In this case the relatively crude information contained in the grade may be of use farther upstream, for intermediaries who may need to exchange lots of fruits or vegetables without directly observing them. This case contrasts with the grading system for many sorts of meat. For example, the USDA mandates a grade for cuts of beef which depends on the weight of the entire carcass and fat cover, information which bears on the fat content of the steak, but which may not be easily inferred from casual observation of a single steak. As a consequence, information on beef grades usually is communicated to the consumer ("Select," "Choice," etc.), though some retail chains in the US see fit to assign more informative grades to the beef they sell (Considine, Kerr, Smith, and Ulmer 1986).

To sum up, grades are meant to summarize a variety of quality characteristics, however, these summaries differ in their value according to both the commodity and place in the production chain. This variation across commodities may explain differences in the conclusions drawn by different authors evaluating the welfare consequences of grading services. For example, Dupré (1990) praises the effects of grading on the Canadian dairy industry while Freebairn (1973) who argues that uniform grading of Australian beef ought to reduce the uncertainty faced by consumers, and Marette, Crespi, and Schiavina (1999) argue that olive oil ought to be graded since magnetic resonance imaging is necessary to detect the fraudulent use of non-olive oils. These are all cases in which grade arguably conveys information to the final consumer above and beyond what that consumer might be able to observe at the supermarket. Thinking of horticultural commodities, Bockstael (1984) and Hollander, Monier, and Ossard (1999) argue that a competitive industry will, by itself, provide the efficient amount of grading. ${ }^{2}$

In this paper we will consider the case of a grading system as a special case of a system in which producers observe some vector of characteristics, intermediaries observe some second vector, and consumers a third. These different vectors need not be exclusive; for example, consumers' information may be a superset of the information of the intermediary. In a

\footnotetext{
${ }^{2}$ This raises the issue of how to design an optimal grading system, a topic considered by Berck and Rausser (1982) and Bockstael (1987), but which is beyond the scope of this paper, which will henceforth assume that the information provided by grade is determined exogenously.
} 
similar spirit, Bockstael (1984) assigns existing research on grading and quality standards into four distinct categories, according to to whether or not consumers or producers can make decisions which influence the quality of produce they consume or produce. The models presented in this paper transcend Bockstael's categorization by introducing uncertainty (consumers and firms may be able to draw imprecise inferences about quality) and an additional set of actors (employees or contractors to the firm), but the spirit of her typology remains intact: what firms and consumers observe about quality and when they observe it is of crucial importance.

The remainder of the paper proceeds as follows. In Section 2, we sketch some simple models which differ only regarding their information structure, and make some simple observations regarding the implications of these different models for welfare and industry structure, with each model accompanied by an illustrative example. Section 3 concludes.

\section{MODELS}

In this section we develop a short sequence of models, designed to illustrate the different issues having to do with both the consumers and producers of a good of variable quality. As indicated above, the chief distinction between these models has to do with who observes what. We imagine three different kinds of actors: producers, who actually cultivate crops, grow livestock, and so on; intermediaries, who obtain agricultural commodities from the producers, and then sell it to the third sort of actors, consumers. We denote by $a$ some set of actions taken, investments made, or information observed by the producer; this is, in some sense, the information generated by the producers, which may or may not be shared with intermediaries and consumers. Similarly, we denote by $b$ the information generated by the intermediary; think of this as the measurement of quality characteristics, when this occurs, and assume that $b$ is conditionally independent of $c$. Finally, the information generated by the consumer, $c$ may include informal quality measurement (squeezing apples, for example), and also include the utility actually derived from consumption.

Our first model (Section 2.1) serves as a sort of benchmark. In the benchmark model, we imagine that while production is uncertain, in the sense that a given set of inputs yields an output of variable quality, subsequent to harvest all relevant quality attributes are observable to all parties: when shopping for apples at a supermarket, for example, a consumer specifies a particular set of quality characteristics which completely capture all "payoffrelevant" information-given this information, the consumer knows exactly what utility he will derive from later consuming the apple. We think of this as the actual quality of the commodity, $c$. All parties costlessly observe production related information $a$ as well as final quality $c$. Because all parties 
costlessly observe all relevant attributes of the foodstuff, no grading system can provide any additional useful information in this model. We characterize the solution to the problems facing producers, intermediaries, and consumers, and construct a competitive equilibrium for a particular specification of consumer preferences.

For contrast, in our second model (Section 2.2) we suppose that no quality attributes are observable: every consumer necessarily buys a "pig in a poke." Although consumers know how much utility they derive from their purchase ex post (that is, consumers know c), these "preference shocks" are assumed to be unobservable. Further, though consumers may be able to observe production practices $a$, they can't associate different values of $a$ with the resulting product, a situation that many authors (e.g., Bockstael (1984), Hennessey (1995)) liken to Akerlof's (1970) "lemons" problem. As a consequence, there is only one price for any given kind of foodstuff, regardless of quality, with obvious consequences for firms' incentives to produce higher quality goods.

Our third model (Section 2.3) maintains the assumption that quality (and subsequent utilities) are unobservable, but that some grading characteristics can be observed, and that these characteristics can be used to infer quality, albeit with imperfect precision. These observable characteristics can be interpreted as grades, or (perhaps better) as the kinds of measurements which might be used in grading.

The fourth model we construct (Section 2.4) extends our notion of grading to permit firms and consumers to observe different sets of grading characteristics. Returning to our example of a consumer purchasing apples, we have in mind that consumers may be privy to some information which may be difficult for the supermarket to observe. For example consumer A, who has previously eaten an apple from particular bin, might provide some word-of-mouth information on the sweetness of the apple to consumer B, or consumer B might have previously eaten an apple from the bin himself. Alternatively, the consumer may engage in a very detailed inspection of a small number of apples, of the sort which may be too costly for the firm to engage in. This reduces the uncertainty faced by consumers, of course, and in equilibrium provides incentives to produce goods of higher quality.

Finally, (Section 2.5) we suppose that the production characteristics $a$ cannot be directly observed by either intermediaries or the consumer, but which is observed by producers. As a consequence, though intermediaries and producers can't directly observe $c$, it's possible to infer something about the characteristics consumers observe by looking either at the quantities demanded or realized prices. This final model delivers the setting considered by Hueth and Ligon (1999), in which (if arrangements are efficient) these employees or contractors bear some "price risk," since prices are a signal 
associated with consumers' private perception of some quality characteristics.

2.1. Observable Quality. In this section we develop a benchmark model of quality, in which firms make decisions which influence the quality of goods supplied to consumers, and in which consumers observe the quality of goods prior to making a purchase. In spirit, this benchmark model is very close to that of Bockstael (1984), though in her model quality is assumed to be discrete, and there is no uncertainty.

\section{Consumers.}

Begin by considering the problem facing a person who consumes a single, indivisible unit of some foodstuff of variable quality, $c \in C \subset \mathbb{R}$, and who also values consumption of some other composite commodity, $x \in X$. The consumer's preferences over these two goods are given by a utility function $U: X \times C \rightarrow \mathbb{R}$, assumed to be strictly increasing in either argument, weakly concave, and continuously differentiable.

Now, imagine our consumer at the grocery store, trying to decide what produce to purchase. We take the price of the composite good to be $n u$ meraire, and imagine that produce of every quality can be found at the grocery store, with produce of quality $c$ sold at a price of $p(c)$. Given this environment, the consumer can reduce expenditures on other goods in order to purchase higher quality produce, solving the problem

$$
\max _{c \in C} U(x-p(c), c) .
$$

Here we can interpret $x$ as the expenditures on the composite commodity when the consumer makes no purchases of the foodstuff. Now, if the price function $p(c)$ is continuously differentiable, then the first order condition associated with (1) is simply

$$
p^{\prime}(c)=\frac{U_{c}(x-p(c), c)}{U_{x}(x-p(c), c)},
$$

where $p^{\prime}$ denotes the marginal change in price with a change in quality, $U_{x}$ denotes the marginal utility of $x$, and $U_{c}$ of $c$, so that consumer equates the marginal increase in price with his marginal rate of substitution between $x$ and $c$. Note, however, that care must be taken in interpreting this condition: if $p$ is not convex, then the first order condition may not characterize the consumer's optimum. Note that an increase in the price of "quality" is best thought of as an increase in the derivative $p^{\prime}(c)$. Also note that so long as the cross-partial $U_{x c}(\cdot, \cdot)$ is not too large and negative, then quality will be a normal good for this consumer; increases in income translate into increases in the quality of the goods demanded. 
Producers.

Producers are taken to be the actors who make the management decisions, investments, and actions necessary to actually produce some agricultural commodity. Producers have the same preferences as consumers, but we'll find it convenient to work with the indirect utility function, denoted $V(w, \vec{p})$, where $w$ is the producer's income, and $\vec{p}$ is a vector of prices, which are taken as given by the producer. In addition to consuming, the producer takes some costly action $a \in A \subset \mathbb{R}$, which determines the joint distribution of quality characteristics $c$, and the information generated by the firm $(b)$, given by $F(b, c \mid a)$. The wage received by producers is determined via negotiations with a firm, but in general may be contingent on any of the variables $a, b$, or $c$. Since the producer controls only $a$, his problem is to solve

$$
\max _{a \in A} \int V(w(a, b, c)-a, \vec{p}) d F(b, c \mid a)
$$

Firms.

We turn next to the problem facing a representative firm in this environment of observable quality. Firms in this environment serve as intermediaries, hiring or contracting farmers to produce agricultural commodities, and then marketing the produce to consumers. The firm orders the producer to take action $a$, observes quality measurements $b$, and also observes quality characteristics $c$, just as consumers do. We denote by $f(b, c \mid a)$ the conditional pdf of $(b, c)$, and assume for simplicity that $f(b, c \mid a)>0$ for all $(b, c) \in B \times C$ and $a \in A$. Firms are assumed to take prices $p(c)$ as given, so that a profit-maximizing firm solves the problem

$$
\max _{\left.a \in A,\{w(a, b, c)\}_{(} a, b, c\right) \in A \times B \times C} \int[p(c)-w(a, b, c)] d F(b, c \mid a),
$$

subject to offering a set of wages guaranteeing the producer a utility of at least $\underline{U}$,

$$
\int V(w(a, b, c)-a, \vec{p}) d F(b, c \mid a) \geq \underline{U} .
$$

Using our assumption that $b$ and $c$ are conditionally independent, this problem yields the first order conditions

$$
\int p(c) \frac{f_{a}(c \mid a)}{f(c \mid a)} d F(c \mid a)=\lambda V^{\prime}(w(a, b, c)-a \mid \vec{p})
$$

and

$$
1=\lambda V^{\prime}(w(a, b, c)-a \mid \vec{p})
$$


where $f(c \mid a)$ is the marginal conditional density of $c$, and where $\lambda$ is the Lagrange multiplier associated with the participation constraint (4). Note from the first of these first order conditions that the farmer's compensation $w(a, b, c)$ turns out to depend optimally only on $a$, and from the combination of the two constraints that the firm will instruct the farmer to choose $a$ such that $\operatorname{Ep}(c) f_{a}(c \mid a) / f(c \mid a)=1$.

We briefly examine the relationships which emerge between farmers and intermediaries in this environment. First, since quality $c$ is directly observable by all parties, there turns out to be no role for quality measurements $b$ (mathematically, this is revealed by the fact that $b$ integrates out of the firm's first order conditions). Second, producers in this environment bear no risk and make no real decisions; they simply follow directions from the firm, and receive a non-contingent salary in exchange. Thus, in an environment with observable actions $a$ and observable quality $c$, we expect something like perfect vertical integration to emerge as the most efficient organizational form.

\section{Equilibrium.}

Definition 1. A competitive equilibrium in qualities is a distribution of incomes across households $G(x)$, a price function $p(c)$, an investment level for firms of $a$, and an allocation of qualities $c$ to a consumer with income $x$ of consumer $d(c, x)$ such that

1. Given the price function $p(c)$ and any income $x, d(c, x)$ solves (1), the problem facing a consumer with income $x$;

2. Given the price function $p(c), a$ solves (3), the firms' problem of choosing investments to maximize profits;

3. Firms' expected profits are zero, or

$$
\int p(c) d F(c \mid a)=w(a) ; \text { and }
$$

4. Markets clear for commodities of almost every quality, or

$$
\iint_{\underline{c}}^{c} d(\hat{c}, x) d F(\hat{c} \mid a) d G(x)=F(c \mid a)
$$

for all $c \in C$.

\section{Example.}

Here we assume a particular parametric form for consumer preferences, and construct an equilibrium for an economy with these preferences. First, note that if preferences are Gorman-aggregable, then one can construct preferences for a representative consumer, of the form $\bar{U}(\bar{x}-p(c), c)$, where $\bar{x}$ is per capita income. Then the demand function for the representative 
consumer will be equal to per capita demand for individual consumers in the economy, with qualities demanded satisfying

$$
p^{\prime}(c)=\frac{\bar{U}_{c}(\bar{x}-p(c), c)}{\bar{U}_{x}(\bar{x}-p(c), c)} .
$$

Market clearing implies that prices must be such that this first order condition is satisfied for almost all $c$. Now, we select a particular parametric form of Gorman-aggregable preferences, assuming that $U(x, c)=\log x+$ $\alpha \log c$. The preferences of the representative consumer take an identical form, so that any continuous differentiable price function must satisfy the differential equation

$$
p^{\prime}(c)=\alpha \frac{\bar{x}-p(c)}{c} .
$$

Solutions to this equation take the form

$$
p(c)=\bar{x}-\frac{k}{c^{\alpha}}
$$

for some constant $k$, determined by the requirement that markets clear. Accordingly, while the exact value of $k$ depends on the pdf $f(c \mid a)$, for any pdf market clearing implies $k>0$. A complete description of an equilibrium would involve specifying a particular pdf, and then finding a pair $(k, a)$ to solve (7) and (3).

2.2. Unobservable Quality. To this point, we've made the extreme assumption that the quality of agricultural produce can be costlessly assessed, so that a different price $p(c)$ can be charged for every possible quality. This may be a reasonable assumption for some kinds of commodities-bananas in a US supermarket, for example, differ in quality mainly according to their ripeness, which is easily evaluated by even casual inspection. However, it's not difficult to think of other kinds of quality characteristics which are not easily observed. Now let us suppose that the opposite is true: that when the consumer purchases a unit of this indivisible foodstuff, he does so in complete ignorance of its quality; the quality of the purchased good is revealed only when the foodstuff is actually consumed. Some version of this model lies at the heart of much earlier research on the welfare effects of minimum grading standards (Price 1967). The consumer knows the distribution of different quality outcomes, given actions and investments $a$ taken by producers, the probability distribution $F(c \mid a)$ introduced in Section 2.1. The consumer now has no real choice to make, since there's no way to choose among different qualities. So long as he consumes any of the foodstuff, his 
expected utility is now given by

$$
\int U(x-p, c) d F(c \mid a)
$$

Since $U$ is concave by assumption, the problem facing a social planner will also be concave. As a consequence the addition of uncertainty unambiguously reduces welfare, despite the fact that the firm can now charge only a single price $p$, which may be smaller than the price paid when quality is observed. If minimum quality standards could somehow be enforced despite the unobservability of $c$, then the imposition of such standards could be welfare improving, as in Price (1967). However, it's hard to imagine a useful characteristic which could be observed by a third party grader but not by firms or consumers.

2.3. Grading. Next we consider a sort of hybrid of the models of the previous two sections. Quality is not directly observable, but some other random variable (the grade, denoted by $b \in B$ ) can be observed by both producers and consumers. Furthermore, while grade does not generally allow one to perfectly infer quality, it may provide some information. In particular, let $f(c, b \mid a)$ denote the joint pdf of quality and grade conditioned on action $a$ taken by producers, while $f(c \mid b, a)$ denotes the distribution of unobserved quality conditioned on both grade and action, and $f(b \mid a)$ denotes the pdf of grade conditioned only on action. With this new notation in place, analysis proceeds much as in Section 2.1, with the difference that prices and ex ante consumer payoffs depend only on $b$. In particular, the consumers' problem becomes

$$
\max _{b \in B} \int U(x-p(b), c) d F(c \mid b, a),
$$

while firms solve

$$
\max _{a \in A} \int p(b) d F(b \mid a)-w(a),
$$

where wages $w(a)$ paid to producers are determined as in Section 2.1. A competitive equilibrium in this setting is analogous to the equilibrium defined in Section 2.1, but with the consumer's problem given by (10), the firm's problem by (11), and with prices indexed only by $b$, rather than by $c$.

Relative to the model of Section 2.1, this problem involves greater uncertainty, both for consumers (what is the utility which will be derived from consuming foodstuff of grade $b$ ?) and for firms (what's the actual quality of goods sold at price $p(b)$ ?). The concavity of the firms' and consumers' problems implies that this additional uncertainty results in a welfare loss. Two consequences of interest stem from this potential welfare loss. First, it may be worthwhile to make investments to improve grading. If consumers 
are better able to infer the quality of foodstuffs, then this extra information has value. Second, the strong conclusions drawn by Bockstael (1984) in an environment with quality being perfectly observable (minimum quality standards are always welfare-reducing) also apply to this more general setting, since consumers can always choose not to purchase goods which are likely to be of low quality, based on their observable grade.

\section{Example.}

A recent example of this sort of grading problem is given by Chalfant, James, Lavoie, and Sexton (1999), who consider the problem of sizing prunes. Whole prunes are often packaged in such a way that consumers can't choose individual prunes based on size; instead they must select a package of prunes, drawn from the distribution of graded prunes. The chief element involved in prune grading is size. Prunes (and many other kinds of fresh produce) are sized by conveying them over a surface with holes of increasing size; once a prune reaches a hole larger than the diameter of the prune, it (usually) falls through into a bin of similarly sized prunes. Occasionally, however, a prune of fixed size fails to fall into the smallest hole through which it could fit, and instead falls through a hole meant to capture larger prunes. Note that the converse never happens.

In its design of a grading scheme, the prune industry appears to take the position that the quality characteristic valued by consumers is the weight of the prune, not its diameter. Accordingly, in this environment, we can think of the relevant quality characteristic, $c$, as just reflecting prune weight, and can think of the grade $b$ as the radius of the prunes which are supposed to fall into a particular bin. If all prunes were perfect spheres of identical density, and if all prunes fell into the correct bin, then $c$ and $b$ would be related by $c=k b^{3}$, where the constant $k$ is just $4 / 3 \pi$ times the density of the prune. Since neither of these premises is exactly correct, $c$ and $b$ are actually related by $c=k b^{3}+\epsilon$, where $\epsilon$ is a grading error.

A nice feature of the paper is that the authors actually conduct experiments which allow them to construct precise engineering estimates of the distribution of $\epsilon$; producers are assumed to be able to affect the size distribution of prunes by engaging in the costly practice of shaking trees, which tends to dislodge particularly small fruit. Using their estimates of grading error, the authors argue that this error leads to both lower consumer welfare and underinvestment in tree-shaking. ${ }^{3}$

\footnotetext{
${ }^{3}$ And claim that this is due to an "adverse-selection" problem. Because there's no asymmetry of information in their model, this seems an unusual use of the term. A sensible extension of this example might be to suppose that tree-shaking is unobservable action, leading to an information asymmetry of the sort considered below in Section 2.5, but even this would be an example of moral hazard, not adverse selection.
} 
2.4. Consumer Grading. Here we suppose that the intermediary can engage in quality measurement and grading, as in the previous section, but also that the consumer has some independent information which helps him to predict the utility derived with the consumption of some commodity. To model this, we modify the notation above, writing $c=h\left(c_{1}, c_{2}\right)$. The idea is that realized quality $c$ is a function of characteristics $c_{1}$ observed by the consumer prior to purchase (think of a shopper checking the firmness of apples), and other characteristics (think of sweetness) observed only upon consumption. ${ }^{4}$

In this environment, prices can depend on measured characteristics $b$ and also characteristics observed by consumers in advance of purchase $c_{1}$. As a consequence, the problem facing consumers is

$$
\left.\max _{\left(b, c_{1}\right) \in B \times C_{1}} \int U\left(x-p\left(b, c_{1}\right), h\left(c_{1}, c_{2}\right)\right) d F\left(c_{2}\right) \mid b, c_{1}, a\right)
$$

while firms solve

$$
\max _{a \in A} \int p\left(b, c_{1}\right) d F\left(b, c_{1} \mid a\right)-w(a) .
$$

The additional information observed by the consumer reduces uncertainty, ceteris paribus. However, since only characteristics $c_{1}$ affect prices received by producers, quite perverse outcomes are possible when $c_{1}$ and $c_{2}$ aren't independent.

\section{Example.}

Here we report on a small experiment conducted by the author in the spring of 1999. We randomly selected four different kinds of "Red Delicious" apples from a local produce market ("small," "large," "extra large," and "organic"). Though we purchased a fairly large number of each kind of apple, we carefully selected them so that there was much more apparent variation across types than within types. We gave 48 experimental subjects the opportunity to visually examine one of each of the four different types of apples, and asked them to rank the apples according to their prediction of utility derived from consuming the apple, based on their visual inspection (their "visual ranking"). We then gave the subjects a blind "taste-test" of the apples they'd ranked, and asked them to rank the apples by utility derived from actual consumption (their ex post ranking).

\footnotetext{
${ }^{4}$ This two-fold distinction is similar to one drawn by Nelson (1970), though he goes farther. Our $c_{1}$ corresponds to what he terms "search" characteristics, and our $c_{2}$ to what he calls "experience" characteristics. He also describes "credence" characteristics, which are valued by the consumer, but never observed. Examples of this last might include beliefs about production characteristics which directly enter consumer utility, such as whether or not a fruit was produced using organic methods.
} 
There was considerable agreement among subjects regarding both visual and ex post rankings, with the average Spearman correlation coefficient between subjects' visual rankings (Friedman's statistic, which is distributed approximately chi-squared with three degrees of freedom for our experiment) equal to 25.7, while the same statistic for the ex post ranking was 10.69 , both highly significant. However, despite this agreement across subjects, visual rankings were a poor predictor of ex post rankings, the average Spearman correlation coefficient between the two rankings being equal to 0.23 (not significantly different from zero). This average hides the considerable heterogeneity in the apparent ability of subjects to use visual characteristics to predict ex post rankings. The modal Spearman correlation coefficient was 1 , but if one sets aside these "perfect" predictors, then the average Spearman correlation coefficient drops to -12.41 . Fourteen of the subjects gave predictions nearly the reverse of the ex post outcome (i.e., the apple they thought would be their favorite was in fact their least favorite; the apple they thought would be their second favorite was in fact their second least favorite, and so on). A firm marketing apples to these latter subjects would have done well to encourage growers to produce apples with appealing visual characteristics (large and particularly red in color) which actually turn out to be negatively related to appealing taste in this sample. ${ }^{5}$

2.5. Contractor Investment. In each of the models considered so far, production information $a$ is observed not only by the producer, but also by the firm. As a consequence, the contractual arrangements made between the firm and producers have looked very much as though the grower is simply a salaried employee of the firm-all risk in quality outcomes is borne by the intermediary, who simply pays the grower for doing his job (taking production decisions $a$, chosen by the firm).

In this section we turn our attention to the case in which the firm can suggest to the farmer that he take actions $a$, but may not be able to verify that the farmer actually follows those suggestions. This treatment is similar to the environment described by Hueth and Ligon (1999), but extends that treatment by being more explicit about the source of variation in prices received by the firm for a particular agricultural commodity. The producer retains considerable autonomy, but as a consequence must also bear some of the risk associated with the decisions he makes. The risk here stems from the possibility that $a$ influences the probability of quality outcomes $c$ in ways which can't be easily measured by the firm.

\footnotetext{
${ }^{5}$ This experiment seems to bear out the anecdotal conclusions drawn from interviews with several Washington State growers of Red Delicious reported in the New York Times.
} 
Thus, in designing the contract, the firm solves

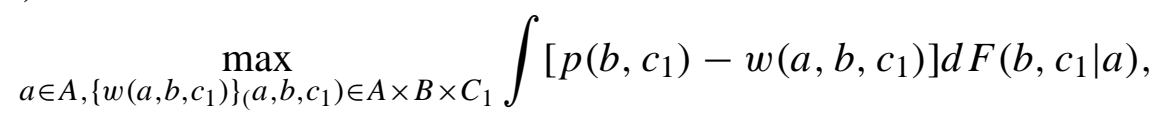

subject to offering a set of wages guaranteeing the producer a utility of at least $\underline{U}$,

$$
\int V\left(w\left(a, b, c_{1}\right)-a, \vec{p}\right) d F\left(b, c_{1} \mid a\right) \geq \underline{U},
$$

and subject also to the requirement that the $a$ recommended by the firm be consistent with the incentives facing the farmer, so that

$$
a \in \underset{\hat{a} \in A}{\operatorname{argmax}} \int V\left(w\left(a, b, c_{1}\right)-\hat{a}, \vec{p}\right) d F\left(b, c_{1} \mid \hat{a}\right) .
$$

Now, if the firm offers the grower a constant compensation $w(a)$, the grower will respond by choosing the least expensive action $\hat{a}$; this is clearly inefficient. However, if the firm is able to only observe $b$ and the price $p\left(b, c_{1}\right)$, the efficient contract will typically expose the grower to some price risk. Assume for simplicity that $p(b, \cdot)$ is invertible, so that knowledge of $b$ and $p\left(b, c_{1}\right)$ permits the firm to infer $c_{1}$. Then, so long as the production problem is suitably concave and the grower is sufficiently risk-averse (Jewitt 1988), any interior solution to the contracting problem will satisfy

$$
\frac{1}{V^{\prime}\left(w\left(a, b, c_{1}\right)-a, \vec{p}\right)}=\lambda+\mu\left[\frac{f_{a}\left(b, c_{1} \mid a\right)}{f\left(b, c_{1} \mid a\right)}+\eta\left(a, b, c_{1}\right)\right],
$$

where $\lambda$ is the Lagrange multiplier associated with the participation constraint (15), $\mu$ is the multiplier associated with the incentive compatibility constraint (16), and $\eta\left(a, b, c_{1}\right)$ is the relative risk aversion of the producer. Note that when the incentive compatibility constraint isn't binding, then we recover the constant compensation for growers seen in previous sections; when (16) is binding, then compensation depends on the market price via the likelihood ratio $f_{a}\left(b, c_{1} \mid a\right) / f\left(b, c_{1} \mid a\right)$.

Thus, in this environment it emerges that farmers will bear some of the risk associated with uncertain production of quality; this risk is necessary in order to provide growers with the appropriate incentives to make investments leading to higher quality output. This risk manifests itself in two ways: first, the grower's compensation will depend on the prices ultimately paid by consumers, since these prices allow one to infer what the quality characteristics $c_{1}$ are, which in turn provide some information on the unobserved action $a$. Second, quality measurements $b$ will be of value only when these quality measures improve inference regarding $a$. In a survey of the contracts offered by intermediaries to producers of fruits and vegetables 
in California, the author has found that 59 per cent of fresh market handlers write contracts which expose producers to this sort of price risk, contrasted with only fourteen per cent of processors, suggesting that a model with unobservable contractor investment is appropriate for many fresh market commodities.

\section{CONCLUSiON}

In this paper we interpret "grading risk" to be the kind of uncertainty associated with quality measurement $b$. Risk associated with these measures can effect both consumers and producers, but evaluation of this risk is complicated by the fact that these quality measures also influence prices and the form of the compensation firms offer producers.

We've presented a sequence of models with different assumptions regarding what is observed, and by whom; some stylized results from this sequence are summarized in Table 1. Our first model presumes that producers' actions and final quality characteristics can be observed by all parties. In this model consumers bear no risk (they only purchase commodities of known quality). Less obvious is the result that producers should also bear no risk-firms simply employ agents involved in production, telling them precisely what to do, and awarding them a non-contingent salary. An industry structure of complete vertical integration would deliver efficient outcomes in this environment.

Our second model modifies the first by assuming that quality characteristics can't be observed by any party. Hennessy (1995) likens this environment to the "lemons" model of Akerlof (though Akerlof's model is one of hidden types, rather than of hidden actions); an immediate result is that producers will take the least costly action, which will typically mean that realized quality will be very low. Consumers now face uncertainty having to do with the quality of the goods they purchase; notably, producers still bear no risk, since it's not necessary to provide any incentives to improve quality.

Our third model maintains the assumption that quality is unobservable, but now supposes that the firm can do some kind of grading, which (impefectly) reveals some information regarding quality. In the U.S., it seems likely that beef is a commodity produced largely in accord with this model. In this model, consumers continue to face risk, but the typical quality of the commodity is apt to be much higher. Producers continue not to face riskan integrated packer, for example, may continue to simply compensate the producer according to the actions and investments made by labor.

Our fourth model adds to the third the possibility that consumers may be able to do some informal grading of their own prior to purchase, observing some characteristics which allow them to predict the utility they'll derive if 


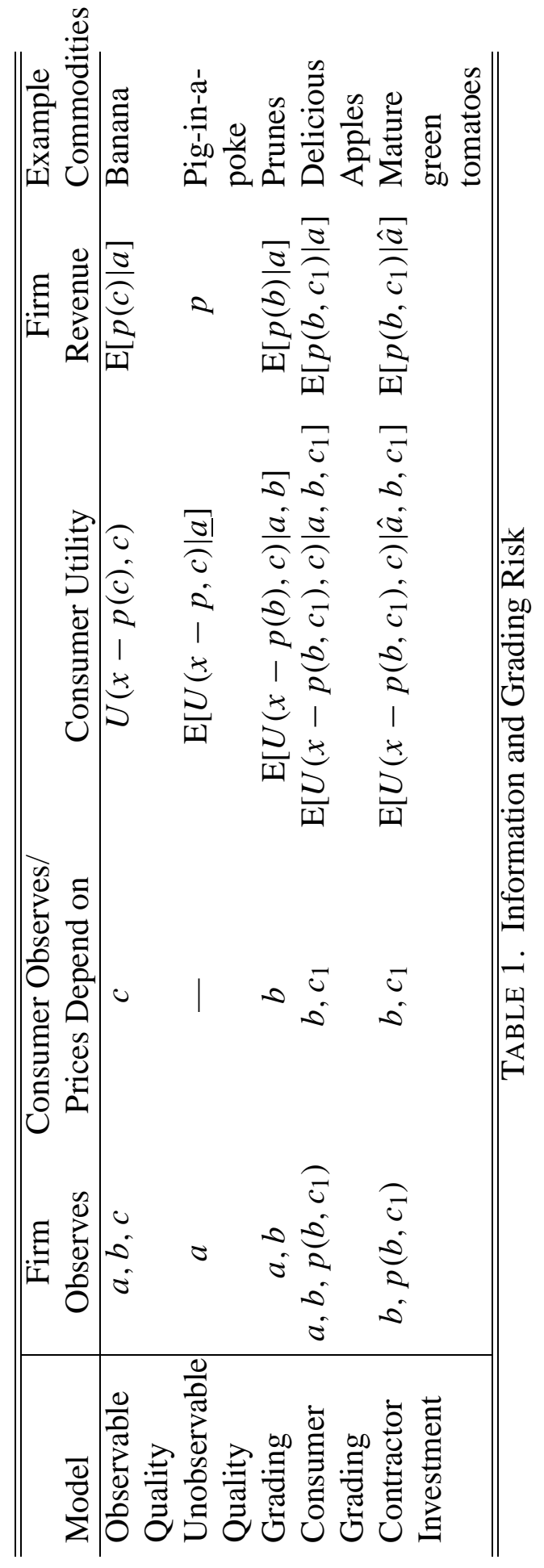


they actually consume the good. An experiment with Red Delicious apples provides some evidence that this sort of informal consumer grading is useful to consumers, but that some uncertainty regarding quality remains.

Our fifth and final model finally relaxes the assumption that the characteristics of the producer are observable. The result is that efficient arrangements between the producer and firm no longer look like an employeremployee relationship, but rather like a contingent contract between two independent parties. In particular, the producer now bears some share of the risk associated with grading and in the prices ultimately paid by consumers. Something like this set of arrangements is consistent with the majority of contracts for fruits and vegetables in California.

\section{REFERENCES}

Akerlof, G. A. (1970). The market for "lemons": Quality uncertainty and the market mechanism. The Quarterly Journal of Economics 84(3), 488-500.

Berck, P. and G. C. Rausser (1982). Consumer demand, grades, and margin relationships. In G. C. Rausser (Ed.), New Directions in Econometrics Modeling and Forecasting in U.S. Agriculture. New York: Elsevier.

Bierlen, R. and O. Grunewald (1995). Price incentives for commercial fresh tomatoes. Journal of Agricultural and Applied Economics 27(1), 138-148.

Bockstael, N. E. (1984). The welfare implications of minimum quality standards. American Journal of Agricultural Economics 66, 466-71.

Bockstael, N. E. (1987). Economic efficiency issues of grading and minimum quality standards. In R. E. Kilmer and W. J. Armbruster (Eds.), Economic Efficiency in Agricultural and Food Marketing, pp. 231250. Ames, Iowa: Farm Foundation.

Chalfant, J. A., J. S. James, N. Lavoie, and R. J. Sexton (1999). Asymmetric grading error and adverse selection: Lemons in the California prune industry. Journal of Agricultural and Resource Economics 24(1), 57-79.

Considine, J. I., W. A. Kerr, G. R. Smith, and S. M. Ulmer (1986). The impact of a new grading system on the beef cattle industry: The case of canada. Western Journal of Agricultural Economics 11(2), 184194.

Dimitri, C., J. K. Horowitz, and E. Lichtenberg (1996). Grading services as a mechanism for dispute resolution in fruit and vegetable markets. Manuscript. 
Dupré, R. (1990). Regulating the Quebec dairy industry, 1905-1921: Peeling off the Joseph label. The Journal of Economic History L(2), $339-348$.

Egan, T. (2000, November 4). 'Perfect' apple pushed growers into debt. The New York Times.

Espinosa, J. A. and B. K. Goodwin (1991). Hedonic price estimation for Kansas wheat characteristics. Western Journal of Agricultural Economics 16(1), 72-85.

Freebairn, J. W. (1973). The value of information provided by a uniform grading system. Australian Journal of Agricultural Economics 17, 127-139.

Hennessey, D. A. (1995). Microeconomics of agricultural commodity grading: Impacts on the marketing channel. American Journal of Agricultural Economics 77, 980-89.

Hennessy, D. A. (1995). Microeconomics of agricultural grading: Impacts on the marketing channel. American Journal of Agricultural Economics 77, 980-989.

Hollander, A., S. Monier, and H. Ossard (1999). Pleasures of cockaigne: Quality gaps, market structure, and the amount of grading. American Journal of Agricultural Economics 81(3), 501-511.

Hueth, B. and E. Ligon (1999). Producer price risk and quality measurement. American Journal of Agricultural Economics 81(3), 512-524.

Jewitt, I. (1988, September). Justifying the first-order approach to principal-agent problems. Econometrica 56(5), 1177-1190.

Lancaster, K. J. (1966). A new approach to consumer theory. Journal of Political Economy 74(1), 132-157.

Marette, S., J. M. Crespi, and A. Schiavina (1999). The role of common labelling in context of asymmetric information. Manuscript.

Nelson, P. (1970). Information and consumer behavior. Journal of Political Economy 78, 311-329.

Price, D. W. (1967). Discarding low quality produce with an elastic demand. Journal of Farm Economics 49, 622-632.

University of CALIFornia, BERKELEy, AND MEMber of the GiANNini FounDATION.

E-mail address: ligon@are.berkeley .edu 